\title{
Choice of Development Path of Leisure Agriculture Based on Circular economy
}

\author{
Jiajia Qin \\ Jiangxi Biotech Vocational College, Jiangxi, Nanchang,330200
}

Keywords: Circular economy; Leisure Agriculture; Development path

\begin{abstract}
Leisure agriculture is to integrate rural resources together and develop a tourism industry chain through these rural resources. Because with the development of the times, the pace of people's life is getting faster and faster. Although the material living standard has been improved, but the spiritual life is becoming more and more empty, and leisure agriculture can help people relax and feel the beauty of nature. This paper mainly focuses on the development path of leisure agriculture based on circular economy.
\end{abstract}

\section{The significance of developing Leisure Agriculture}

\subsection{It is beneficial to promote the adjustment of industrial structure in rural areas.}

Agriculture has always been a major industry that our country has to mention, agriculture has also made a lot of contributions to the economic development of our country, and because of the rapid development of cities in recent years, it has promoted the development of agricultural economy. However, there are still many gullies in the rural economy and the urban economy. In order to promote the development of rural economy, so that the rural economy can become comparable to the existence of urban economy, we must develop a sustainable road suitable for rural development. The emergence of leisure agriculture model provides more choices for agricultural economic development. Through leisure agriculture, more and more people come to the countryside to spend. And these consumption itself is an economic behavior, so it also drives the development of the rural economic market, and the countryside is now also beginning to integrate rural resources to form a rural tourism industry chain, in which tourism products also contribute a lot of profits. And also because of the emergence of leisure agriculture model, rural areas get more opportunities for development.

\section{2 conducive to the expansion of the scope of agricultural products in rural areas}

Leisure agriculture is a kind of tourism mode. Through leisure agriculture, people can feel the tranquility of rural life, but also experience the beauty of rural scenery. At the same time, in rural areas, people can also buy fresh agricultural products that are rare in the city. Even, the sale of rural agricultural products can connect directly with the people who come to the countryside for tourism. This not only saves a lot of costs, but also saves the redundant resale links. It has also created more income for farmers. In addition, leisure agriculture also gives agricultural products a richer cultural connotation, so the value of agricultural products can also be improved.

\section{The principle of developing Leisure Agriculture under the guidance of Circular economy}

\section{1 pollution reduction principles}

With the rise of leisure agriculture, the pollution situation in rural areas is becoming more and more serious. In order to make leisure agriculture sustainable development, we must vigorously curb the pollution and protect the ecological environment. And if you want to reduce pollution, there is indeed a certain degree of difficulty. Because pollution occurs in the production process of tourism products, and if leisure agriculture can be developed and the rural environment can be protected, it is necessary to meet the consumer needs of tourists on the basis of cost saving. And this is not only that the rural tourism model needs to be paid attention to, all tourism models should pay attention to, 
the development of tourism resources should be moderate, only to protect the environment. Be able to achieve sustainable development. However, there are still many neglect of environmental protection for the sake of economic development, especially in the Golden week of Tourism, the pollution will be even more serious.

\section{2 principle of waste Recycling}

Leisure agriculture is now a favorite tourism project for urban residents, so the demand for tourism resources is increasing, and in this process, the pollution situation will become more and more serious. Rural areas should follow the theory and policy concept of circular economy, strengthen the recovery of resources, establish waste recycling bin, then not only the environment can be beautified, but also the cost can be reduced.

\section{3. the choice mode of developing leisure agriculture from the perspective of circular economy}

As with the development of leisure agriculture and other industries, it is necessary to improve the core competitiveness, and only the core competitiveness can bring more consumers and promote the development of the economy. Therefore, the leisure agriculture should follow the principle of circular economy and explore the appropriate characteristic development road.

\subsection{Environment-oriented mode}

The environment of leisure agriculture is different from that of other tourism industries. In leisure agriculture projects, people mainly visit the rural environment and experience rural life. At the same time, they can also buy rural green agricultural products. Thus it can be seen that the importance of environment to the development of leisure agriculture, only in the case of beautiful rural environment, can attract more tourists, so for the sustainable development of leisure agriculture. Local farmers and tourists should work together to protect the environment and avoid environmental pollution.

\subsection{Cultural orientation model}

The history of the Chinese nation is very long. In the long historical process, the Chinese nation has formed a unique historical background, which will have different historical backgrounds in different regions, and different historical backgrounds have also created different national cultures. These are very attractive to the people in the city, and leisure agriculture is to provide these people with an opportunity to personally feel the smell of national culture and the magic of folk skills in these places. This is also a very good opportunity for the development of leisure agriculture. Leisure agriculture can be culture-oriented, follow the principles of circular economy development, and go out of the way. One of the characteristics of the road.

\section{Exploration on the Development path of Leisure Agriculture based on Circular economy}

The status of leisure agriculture is getting higher and higher under the background of rapid development of society, because leisure agriculture is based on circular economic foundation, and the concept of circular economy is the concept that must be adhered to in the implementation of sustainable development strategy. By exploring the development mode of leisure agriculture, we can find out the most suitable ways for the development of leisure agriculture.

\section{1 highlight the characteristics of leisure agriculture}

Whether it is the development of the leisure agriculture or the development of other economic industries, it is necessary to have the complete strategic planning as the guide, and to strengthen the core competitiveness, has the core competitiveness, can gain a place in the competitive market, The core competitiveness of the leisure agriculture is that the leisure agriculture is different from the other tourism industry, for example, the cultural factors and the dietary factors in the leisure agriculture industry, these are the characteristics of the leisure agriculture. These features can also 
help the leisure agriculture to get a clear location, build a unique leisure agriculture model, and can also play a role in the construction of a new socialist countryside.

\section{2 focus on protecting the ecological development of leisure agriculture}

If we want to improve the income of farmers, we must vigorously develop leisure agriculture, but the way to develop leisure agriculture is not to rely on blind construction of leisure agriculture. Because leisure agriculture mainly attracts tourists by sightseeing nature and green agricultural products, leisure agriculture must also constantly improve environmental facilities and strengthen tourist services. Only by following the theory of circular economy and strengthening the protection of ecological environment can we develop sustainably. In fact, the sustainable development of ecological environment also promotes the sustainable development of leisure agriculture.

\section{Conclusion}

In a word, for the ecological environment, the development of modern tourism is actually a threat, but economic development is also necessary. In order to promote economic development and maintain the ecological environment, then we should follow the principle of circular economy, and leisure agriculture, as a tourism industry that depends entirely on the ecological environment, pays more attention to the ecological environment and avoids the occurrence of pollution as far as possible.

\section{Acknowledgment}

Fund project: Supported by the earmarked fund for jiangxi Agriculture Research System (number: JXARS-15-planning programming)

\section{References}

[1]A study on the development path of leisure agriculture of Liu, Yan and eight reservoirs is based on the perspective of ecological economy [J]. Liu Jia, Liu Yanhua. China's collective economy. 2015 (18)

[2] Analysis of the application of green supply chain management in the development of leisure agriculture: a case study of Jiangning District, Nanjing City [J]. Zhai Weizhen, Wang Ling. The vision of science and technology. 2015 (16)

[3] The general layout and countermeasure research of urban and leisure agriculture in the mountain area[J]. Zhou Ying, Miao Pengfei, Gan Shouwen, Li Hu. Modern agricultural science and technology. 2014 (24)

[4] The choice of leisure agriculture development path based on low-carbon economy[J]. Ma 'o-ming, Zheng Xiaoyun. Chinese and foreign entrepreneurs. 2014 (05)

[5] The development path of leisure agriculture in Hebei province. Take the development of leisure agriculture in Qinhuangdao as an example[J]. Hao Yange, Sha Yanrong. The market is modern. 2010 (16)

[6] Ecological chain-based leisure agriculture development model _ Tourism circular economy study of Beijing crab island resort[J]. Zou series. Journal of the second foreign language institute of beijing. 2005 (01)

[7] Research on leisure agriculture from the perspective of circular economy [J]. Wei Fen, Ding Zhien. Low temperature and superconductivity. 2014 (03)

[8] Literature review of island circular economy [J]. Cao Mengyun. Environmental protection and circular economy. 2019 (08) 